\title{
Development of Nanocomposite Film Comprising of Polyvinyl Alcohol (PVA) Incorporated with Bacterial Cellulose Nanocrystals and Magnetite Nanoparticles
}

\author{
Naphat Usawattanakul ${ }^{1}$, , Selorm Torgbo ${ }^{1,2}{ }^{\oplus}$, Prakit Sukyai ${ }^{1,2, *}$, Somwang Khantayanuwong ${ }^{2,3}$, \\ Buapan Puangsin ${ }^{2,3}$ (D) and Preeyanuch Srichola ${ }^{2,4}$
}

1 Biotechnology of Biopolymers and Bioactive Compounds Special Research Unit, Department of Biotechnology, Faculty of Agro-Industry, Kasetsart University, Chatuchak, Bangkok 10900, Thailand; naphat.pop@gmail.com (N.U.); selorm.t@ku.th (S.T.)

2 Cellulose for Future Materials and Technologies Special Research Unit, Department of Biotechnology, Faculty of Agro-Industry, Kasetsart University, Chatuchak, Bangkok 10900, Thailand; fforsok@ku.ac.th (S.K.); fforbpp@ku.ac.th (B.P.); preeyanuch.anu@ku.th (P.S.)

3 Department of Forest Products, Faculty of Forestry, Kasetsart University, Chatuchak, Bangkok 10900, Thailand

4 Kasetsart Agricultural and Agro-Industrial Product Improvement Institute, Kasetsart University, Chatuchak, Bangkok 10900, Thailand

* Correspondence: fagipks@ku.ac.th

\section{check for} updates

Citation: Usawattanakul, N.; Torgbo S.; Sukyai, P.; Khantayanuwong, S.; Puangsin, B.; Srichola, P.

Development of Nanocomposite Film Comprising of Polyvinyl Alcohol (PVA) Incorporated with Bacterial Cellulose Nanocrystals and Magnetite Nanoparticles. Polymers 2021, 13, 1778. https://doi.org/ $10.3390 /$ polym 13111778

Academic Editor: José Ignacio Velasco

Received: 27 April 2021

Accepted: 25 May 2021

Published: 28 May 2021

Publisher's Note: MDPI stays neutral with regard to jurisdictional claims in published maps and institutional affiliations.

Copyright: (c) 2021 by the authors. Licensee MDPI, Basel, Switzerland. This article is an open access article distributed under the terms and conditions of the Creative Commons Attribution (CC BY) license (https:// creativecommons.org/licenses/by/ $4.0 /)$.
Abstract: Nanocomposite film of poly(vinyl alcohol) (PVA) incorporated with bacterial cellulose nanocrystals (BCNCs) and magnetite nanoparticles $\left(\mathrm{Fe}_{3} \mathrm{O}_{4}\right)$ is reported in this study. The BCNC$\mathrm{Fe}_{3} \mathrm{O}_{4}$ nanoparticles and PVA film was prepared by in situ synthesis technique using chemical coprecipitation. Different concentrations of $\mathrm{BCNC}-\mathrm{Fe}_{3} \mathrm{O}_{4}(20 \%, 40 \%$ and $60 \% w / w)$ were mechanically dispersed in PVA solution to form the nanocomposite film. Transmission electron microscopy (TEM) analysis of $\mathrm{BCNC}-\mathrm{Fe}_{3} \mathrm{O}_{4}$ nanoparticles showed irregular particle sizes ranging from 4.93 to $30.44 \mathrm{~nm}$ with an average size distribution of $22.94 \mathrm{~nm}$. The presence of characteristic functional groups of PVA, BCNC and $\mathrm{Fe}_{3} \mathrm{O}_{4}$ were confirmed by Fourier transform infrared (FTIR) spectroscopy and $\mathrm{X}$-ray diffraction (XRD) analysis. Scanning electron microscope (SEM) attached energy dispersive spectroscopy (EDS) and vibrating sample magnetometer (VSM) analysis revealed that, the iron content and magnetic property increased with increasing $\mathrm{BCNC}-\mathrm{Fe}_{3} \mathrm{O}_{4}$ content. The saturation magnetizations (MS) value increased from 5.14 to $11.56 \mathrm{emu} / \mathrm{g}$. The PVA/ $\mathrm{BCNC}-\mathrm{Fe}_{3} \mathrm{O}_{4}$ at $60 \%$ showed the highest Young's modulus value of $2.35 \pm 0.16 \mathrm{GPa}$. The prepared film could be a promising polymeric nanomaterial for various magnetic-based applications and for the design of smart electronic devices.

Keywords: bacterial cellulose nanocrystal; magnetite nanoparticles; nanocomposite film; polymeric nanomaterial; polyvinyl alcohol

\section{Introduction}

Magnetite nanoparticles $\left(\mathrm{Fe}_{3} \mathrm{O}_{4}\right)$ are stimuli responsive materials that have gained much attention from researchers worldwide. This is because of its properties such as nanosize, crystallinity, large specific surface area, superparamagnetism and magnetization value [1]. $\mathrm{Fe}_{3} \mathrm{O}_{4}$ have been studied for many technological applications including magnetic resonance imaging, ferrofluids for audio speakers, magnetic recording media, magnetic targeted drug delivery, magnetic hyperthermia, separation and removal of contaminants $[1,2]$ and nucleic acid separation [3]. However, the pristine magnetic nanoparticles are chemically active, and can easily oxidize in air to other forms leading to loss in magnetic properties and dispersibility. Additionally, due to the nano nature of the particles, it may lead to environmental pollution if used without functionalizing to restrict the particles 
from being blown by air [4]. Furthermore, in acidic conditions, the iron oxide may lose its magnetic property due to its susceptibility to acid. Thus, coating layers may be required to keep the magnetic properties for application in diverse fields [5,6]. In this regard, Yantasee et al. prepared superparamagnetic iron oxide $\left(\mathrm{Fe}_{3} \mathrm{O}_{4}\right)$ nanoparticles functionalized with thiol as an effective sorbent material for toxic substances, which have affinity to iron oxide lattices [7]. The thiol-modified magnetic nanomaterial was also reported for gold recovery from dilute solutions [8]. However, the use of synthetic compound as a conjugant for magnetic materials in matrices may pose a lot of environmental challenges.

Recent studies have focused on the design of various nano-adsorbents containing magnetic particles for removal of metal ions for various applications such as wastewater treatment, extraction of genomic DNA, magnetic resonance imaging, drug delivery systems, separation, preconcentration of various anions and cations and bioseparation $[9,10]$. These may be due to the unique characteristics of the nanoparticles pertaining to those applications, which includes the selective and high adsorptive abilities of metal ions and biomolecules, easy and fast production, rapid uptake and easy separation of the magnetic adsorbent through an external magnetic field [11]. The use of magnetic green adsorbents based on natural polymers are gaining ground as good biomaterial with strong adsorption properties [12]. They are also environmentally friendly, sustainable and naturally renewable [13]. Previous studies have been successfully achieved by introducing various polymers such as biodegradable chitosan nanofibers [14], gelatin [15], amino-functionalized [5], dextran [16,17], pullulan [18] and starch [19]. Kloster et al. reported of a magnetic composite film based on alginate as convenient and efficient natural polymer-based adsorbents [12] Aminodextran-coated magnetic nanoparticles and graphene oxide have also been reported for cellular magnetic resonance imaging [20]. Although many natural polymers have been studied as magnetic-composite materials, none of these studies have considered cellulose nanocrystals (CNCs) from naturally pure and non-toxic bacterial cellulose (BC).

In the present study, BCNCs were conjugated with magnetite nanoparticles in PVA to produce magnetic hybrid nanocomposite film. $\mathrm{BCNC}$ is a rigid shape and highly crystalline particle, which was obtained in our previous studies through acid hydrolysis of bacterial cellulose [21]. It has the same properties as cellulose nanocrystals (CNCs) [21,22], and has been utilized in the development of highly biocompatible and biodegradable materials for various applications. The BCNC is non-toxic, biocompatible with rich hydroxyl group and has high surface area appropriate for combining it with other materials [22]. Unlike plant, which requires pretreatment and bleaching before cellulose extraction and subsequent hydrolysis to obtain $\mathrm{CNCs}$, the pristine $\mathrm{BC}$ is naturally pure and does not require further treatment and bleaching after purification from culture medium. The PVA, on the other hand, is a synthetic polymer used for various applications in different industries. It is soluble in water, effective in film forming, has emulsifying and adhesive quality, is biocompatible, has good swelling, is non-toxic and is non-carcinogenic [23,24]. Reddy et al. synthesized nanocomposite of PVA integrated with nickel sulphide nanoparticles for potential application in energy storage devices [25]. PVA filled with zinc sulphide nanoparticles nanocomposite films [26] and PVA with cadmium sulphide nanocomposites [27] have also been reported with enhanced dielectric properties. Furthermore, PVA, polyvinylidene fluoride (PVDF) and nafion composites have been prepared by solution casting for application in sensors, fuel cells and batteries [28]. For the purposes of adsorption and separation, PVA has been used in protein adsorption [29,30], immobilization of lipase [31], nanocomposite device for bioseparation [32], selective adsorption and separation of dyes [33] and gas separation [34]. However, using pristine $\mathrm{Fe}_{3} \mathrm{O}_{4}$ in PVA film could lead to agglomeration, a property that has been reported to affect the "Van der Waals forces and the pull of magnetic dipole" [35]. Polymer coating may be required to promote uniform distribution of $\mathrm{Fe}_{3} \mathrm{O}_{4}$ particles. Therefore, adding $\mathrm{BCNC}$ will stabilize and enhance distribution of $\mathrm{Fe}_{3} \mathrm{O}_{4}$ in PVA to open up its applications.

Despite the prominent features of BCNC and its hydroxyl group as binding site for ions, to the best of knowledge, no studies have been done on using it alongside PVA and 
$\mathrm{Fe}_{3} \mathrm{O}_{4}$ for consideration in the separation process and smart electronic devices. This study used $\mathrm{BCNC}$ to enhance distribution of $\mathrm{Fe}_{3} \mathrm{O}_{4}$ in PVA film with improved mechanical and superparamagnetic properties. The synthesized nanofilm is magneto-responsive and can be manipulated via an external magnetic field. The high hydrophilicity of $\mathrm{BCNC}$ coupled with the superparamagnetic property of the $\mathrm{Fe}_{3} \mathrm{O}_{4}$ nanoparticle, makes it applicable in diverse fields for bioseparation and adsorption of various molecules and pollutants. This could also serve as an environmentally friendly, sustainable and naturally renewable green adsorbents and material for smart electronic devices.

\section{Materials and Methods}

\subsection{Materials}

Komagataeibacter xylinus (TISTR 975) strains was purchased from the Thailand Institute of Scientific and Technological Research, Bangkok, Thailand. Ferrous sulfate heptahydrate $\left(\mathrm{FeSO}_{4} \cdot 7 \mathrm{H}_{2} \mathrm{O}\right.$, Ajax Finechem Pty., Ltd., Auckland, New Zealand), ferric chloride hexahydrate $\left(\mathrm{FeCl}_{3} \cdot 6 \mathrm{H}_{2} \mathrm{O}\right.$, PanReac AppliChem Barcelona, Spain), and poly(vinyl alcohol) (PVA, $\mathrm{Mw}=89,000-98,000$ ) (EMD Millipore Corporation, Darmstadt, Germany) were use in the study. All other reagents used were of analytical grade.

\subsection{Preparation $B C$ and Extraction of $B C N C$}

The BCNC used in this study was previously extracted and reported in one of our studies [21]. For BC preparation, 5\% $(w / v)$ of sucrose and 2.5\% $(w / v)$ of ammonium sulfate were added to coconut water $(100 \mathrm{~mL})$ and sterilized by boiling at $100{ }^{\circ} \mathrm{C}$. After cooling to room temperature, $5 \%$ glacial acetic acid was added as an acidifier to $\mathrm{pH} 4.5$. Komagataeibacter xylinus $(10 \% v / v)$ was then inoculated and left under static condition at room temperature for 5 days to form bacterial cellulose of $5 \mathrm{~mm}$ thickness. The cellulose pellicles were washed and boiled in $1 \%(w / v) \mathrm{NaOH}$ solution for $15 \mathrm{~min}$ at $100{ }^{\circ} \mathrm{C}$ and finally boiled in deionized (DI) water to attain a neutral $\mathrm{pH}(\mathrm{pH}=7)$. After purification, excess water was removed by compressing the $\mathrm{BC}$ and then grinded into powder. The powdered $\mathrm{BC}$ was hydrolyzed by treating with $60 \%(w / w)$ sulfuric acid using the $\mathrm{BC}$ to acid ratio of $1: 20 \mathrm{~g} / \mathrm{mL}$ with continuous stirring at $45^{\circ} \mathrm{C}$. The hydrolysis reaction was stopped by adding distilled water. The sample was subsequently centrifuged at $13,000 \mathrm{rpm}$ for $15 \mathrm{~min}$ at $4{ }^{\circ} \mathrm{C}$ and then washed three times to remove acid residuals. Dialysis was employed to neutralized the BCNC sample and kept in refrigerator for the next stage of the experiment [21]. The BCNC sample was sonicated for $30 \mathrm{~min}$ before being used in further studies.

\subsection{Preparation of $\mathrm{BCNC}$ and $\mathrm{Fe}_{3} \mathrm{O}_{4}$ Powder}

$\mathrm{The} \mathrm{Fe}_{3} \mathrm{O}_{4}$ and $\mathrm{BCNC}$ composite was prepared by in situ coprecipitation under ultrasonic irradiation following the method by [36] with modifications. In summary, $0.125 \mathrm{~mol}$ $(3.375 \mathrm{~g})$ of ferrous sulfate heptahydrate $\left(\mathrm{FeSO}_{4} \cdot 7 \mathrm{H}_{2} \mathrm{O}\right)$ and $0.25 \mathrm{~mol}(6.9575 \mathrm{~g})$ of ferric chloride hexahydrate $\left(\mathrm{FeCl}_{3} \cdot 6 \mathrm{H}_{2} \mathrm{O}\right)$ with $\mathrm{Fe}^{2+}$ and $\mathrm{Fe}^{3+}$ ions in the $1: 2 \mathrm{M}$ ratio were dissolved in $50 \mathrm{~mL}$ ( $25 \mathrm{~mL}$ each) distilled water. BCNC suspension of $50 \mathrm{~mL}(0.0353 \mathrm{~g}$ dry matter $/ \mathrm{mL})$ was mixed with the resultant iron solution and shook for $12 \mathrm{~h}$ under an incubator shaker with $250 \mathrm{rpm}$ at room temperature. After that, $100 \mathrm{~mL}$ of aqueous $\mathrm{NH}_{4} \mathrm{OH}$ was added under the ultrasonic irradiation at $60{ }^{\circ} \mathrm{C}$ for $30 \mathrm{~min}$ in an ultrasonic bath (Elmasonic $\mathrm{S}$ $100 \mathrm{H}$, Singen, Germany), operating at $50 / 60 \mathrm{~Hz}$ with a power of $550 \mathrm{~W}$ under vacuum using the circulating aspirator (Sibata, Model: WJ-20, Tokyo, Japan). Finally, the prepared sample was rinsed with absolute ethanol and DI water, followed by drying in the oven at $60{ }^{\circ} \mathrm{C}$ for at least $6 \mathrm{~h}$ before being grinded into powder. The prepared $\mathrm{BCNC}$ and $\mathrm{Fe}_{3} \mathrm{O}_{4}$ composite was thereafter labeled "BM".

\subsection{Preparation of PVA Film Incorporated with $B M$}

The PVA ( $\mathrm{Mw}=89,000-98,000)$ concentration of $10 \mathrm{~g} / 100 \mathrm{~mL}$ was dissolved on a hot plate using a magnetic stirrer, and kept in an oven at $90^{\circ} \mathrm{C}$ for $12 \mathrm{~h}$ to have a homogeneous 
solution. The nanocomposite film was prepared using digital overhead mixer (IKW rw 20) by heating the PVA solution on a hot plate at $90{ }^{\circ} \mathrm{C}$. Different concentrations of BM $(20 \%$, $40 \%$ and $60 \% w / w$ ) were added and mixed at $200 \mathrm{rpm}$ for $30 \mathrm{~min}$. The resultant hydrogel mixture was gently poured into a petri dish with an average diameter of $14 \mathrm{~cm}$. The spirit level was used to fix the petri dish to ensure uniform surface and even distribution of the hydrogel, then allowed to settle for $30 \mathrm{~min}$ at room temperature to form a film. The film was finally dried in an oven at $40^{\circ} \mathrm{C}$ for $12 \mathrm{~h}$.

\subsection{Characterizations}

Transmission electron microscope (TEM) operated at an accelerating voltage of $80 \mathrm{kV}$ (JEM-2100Plus, Tokyo, Japan) was used to observe the morphology and determine particles size of BM.

The SEM-EDS (Oxford instrument, X-Max, Tehran, Iran) operated at an accelerating voltage of $10 \mathrm{kV}$ was used to observe the atomic composition of iron and elemental mapping of the film.

The chemical interaction of the materials in the film was recorded using the Fourier transform infrared spectrometer (Bruker model Tensor 27, New York, NY, USA) at room temperature using the attenuated total reflectance (ATR) mode.

The crystallinity and characteristic fingerprint of the composite films were measured using an X-ray diffractometer (Bruker D8 Advance, Rosenheim, Germany) with $\mathrm{Cu}$ - $\mathrm{K} \alpha$ radiation and operated at a voltage of $40 \mathrm{kV}$. The scattered radiation was detected at the scan rate of $2^{\circ} / \mathrm{min}$ from $2 \theta=5-70^{\circ}$.

The magnetic responsive behavior of pure $\mathrm{Fe} 3 \mathrm{O} 4$ and their corresponding nanocomposite films, were evaluated using a vibrating sample magnetometer (Model M2000/2100) following [37].

The mechanical properties of composite films were determined according to ASTM D882-02 standard test method using a universal testing machine (Shimadzu model AGS5kN, Kyoto, Japan) as described by [38] with modifications. The films with average dimension of $10 \mathrm{~mm} \times 50 \mathrm{~mm}$ were fitted with a $5 \mathrm{kN}$ load cell, with a crosshead speed of $10 \mathrm{~mm} / \mathrm{min}$ and $3 \mathrm{~mm}$ distance between clamps. The analysis was done in triplicate, and the results were presented as an average value of each film.

\subsection{Statistical Analysis}

The data collected were subjected to the analysis of variance (ANOVA) using GenStat software 12th edition. The multiplicative comparison of means was statistically performed with a Bonferroni test. The experiments were performed with $n=3$ replicates and data presented as the average of three replicates.

\section{Results and Discussion}

\subsection{Morphological and Particle Size Distribution}

Figure 1 shows the TEM image and particle size distribution of BM as nanopowder before using in the PVA matrix. Figure 1a shows an irregular particles sizes ranging from 4.93 to $30.44 \mathrm{~nm}$ with an average size distribution of $22.94 \mathrm{~nm}$ (Figure $1 \mathrm{~b}$ ). Prior to the synthesis of $\mathrm{BM}$, the shape and size of $\mathrm{BCNC}$ and $\mathrm{Fe}_{3} \mathrm{O}_{4}$ nanoparticles were analyzed by atomic force microscopy, which presented varied morphologies of $\mathrm{BCNC}$ and $\mathrm{Fe}_{3} \mathrm{O}_{4}$ (Supplementary Materials Figure S1). The BCNC nanoparticles showed rod-like shapes with an average size of $23.57 \mathrm{~nm}$, whiles the $\mathrm{Fe}_{3} \mathrm{O}_{4}$ showed spherical shapes with average dimension of $4.42 \mathrm{~nm}$. From the TEM result, it could be deduced that the binding of the $\mathrm{Fe} 3 \mathrm{O} 4$ nanoparticles on $\mathrm{BCNC}$ resulted in an increase in particle size. The processing of the two nanomaterials after synthesis through mechanical grinding might have caused the irregularities in shape. The magnetic nanoparticles occur predominantly in cubic and spherical forms. The cubic nanoparticles had lower surface anisotropy due to their flat surface and disordered spins, while the spherical nanoparticles had higher surface anisotropy as a result of their curved surface with more spin surface canting [39]. The 
surface disordering of spins, either as a result of processing method or cladding by BCNC, could cause reduction in saturation magnetization of magnetic particles.

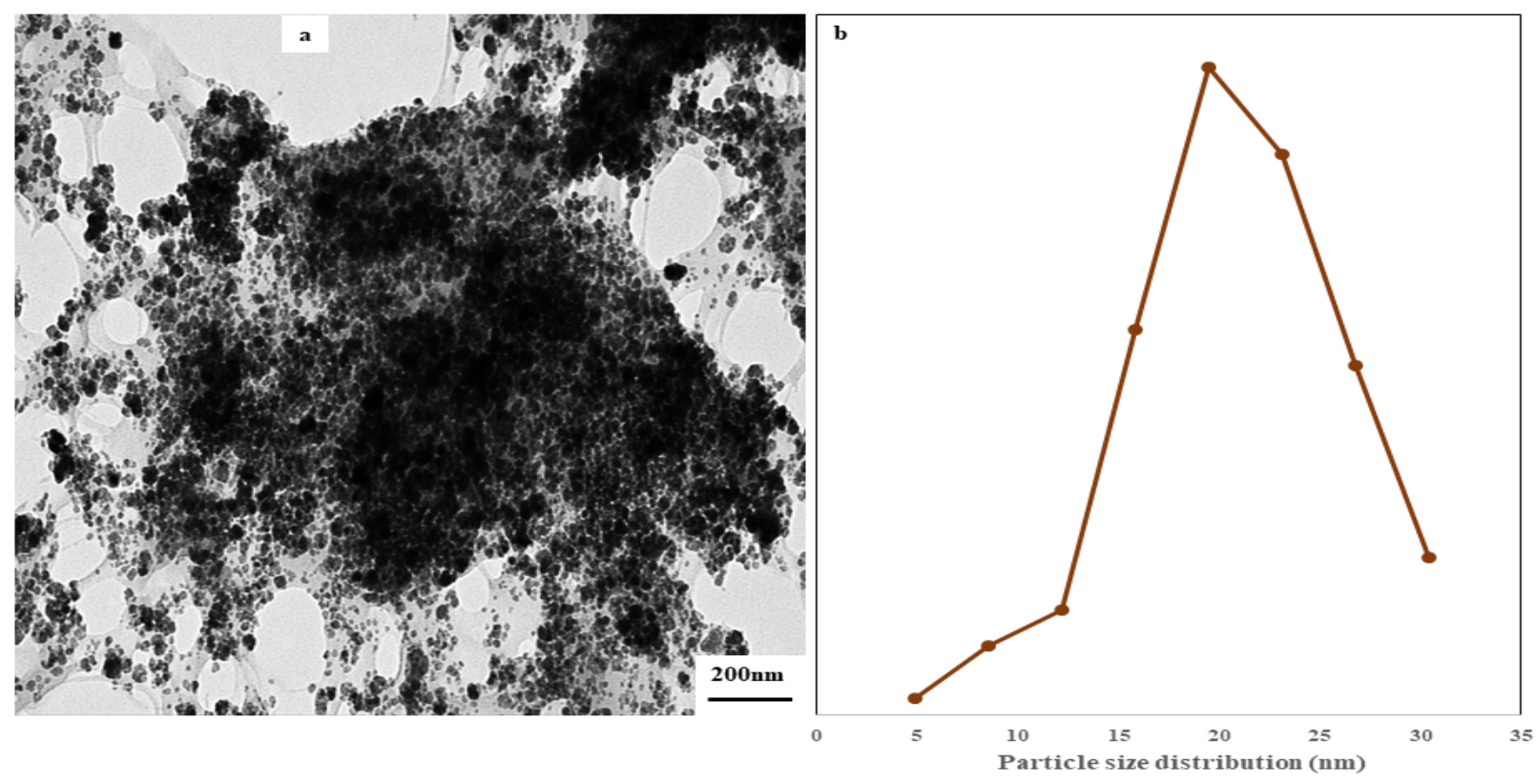

Figure 1. TEM image of $\mathrm{BCNC}$ mixed with $\mathrm{Fe}_{3} \mathrm{O}_{4}(\mathrm{BM})$ powder (a) and particle size distribution (b) of nanoparticles.

\subsection{SEM-EDS Analysis}

The analysis of surface morphology of the films by SEM shows non porous surface with no significant difference between the PVA and the composites films (Figure S2). The presence of $\mathrm{Fe}_{3} \mathrm{O}_{4}$, specifically iron concentration in the composite film, was analyzed by EDS. The sample was prepared by breaking the film in liquid nitrogen and the spectrometry was taken at the break point. The results presented in Figure 2 show varied concentrations of iron in the various composite films, which confirm the presence of $\mathrm{Fe}_{3} \mathrm{O}_{4}$ in the films, while the carbon and oxygen atoms depicted the PVA and BCNC, respectively. As expected, the film with the highest BM content (PVA/BM60) showed the highest percentage atomic peak of $9.09 \%$ for iron in the film (Figure 2c), followed by PVA/BM40 $(4.20 \%)$, while PVA/BM20 showed the lowest atomic peak value of 3.16\% (Figure 2a). This confirms successful dispersion and bonding of $\mathrm{BCNC}$ and $\mathrm{Fe}_{3} \mathrm{O}_{4}$ in the PVA film. This was possible through the formation of a covalent bond between the magnetic particles and hydroxyl group or carboxylic group on the surface of BCNC and PVA. This will serve as a chelating ligand to improve the adsorbing ability of the magnetic composite film with multiple binding sites [40].

The presence and distribution of BM nanoparticles in the PVA matrices was authenticated in the PVA/BM60 film using SEM-EDS elemental smart mapping. The results in Figure 3a shows the distribution of the nanoparticles within the PVA matrices. The various elements present in the nanoparticles (BM) were depicted by different colors as red (iron), yellow (oxygen) and green (carbon) (Figure 3b-e). Figure 4c shows the distribution of Fe in the PVA matrix. It is of interest to note that the Fe was not added to the PVA in isolation but in combination with $\mathrm{BCNC}$, therefore, its distribution in the polymer indicated the stabilizing effects of BCNC. This was established in Figure $3 f$, where the three elements were mapped in the composite film. The uniform distribution of $\mathrm{O}$ and $\mathrm{C}$ in the film was laudable because the two elements were the main component of PVA and BCNC and $\mathrm{O}$ from $\mathrm{Fe}_{3} \mathrm{O}_{4}$. The nanoparticles may be distributed in the polymers through chemical bonding between the various atoms $(\mathrm{O}, \mathrm{C}$ and $\mathrm{Fe})$ in the nanoparticles and the functional groups of PVA [41]. The O-H group of PVA formed hydrogen bond with the $\mathrm{OH}$ and $\mathrm{C}-\mathrm{H}$ 
group of $\mathrm{BCNC}$, which contained $\mathrm{Fe}_{3} \mathrm{O}_{4}$. This interaction within the composite film was further established by FTIR analysis (Figure 5).
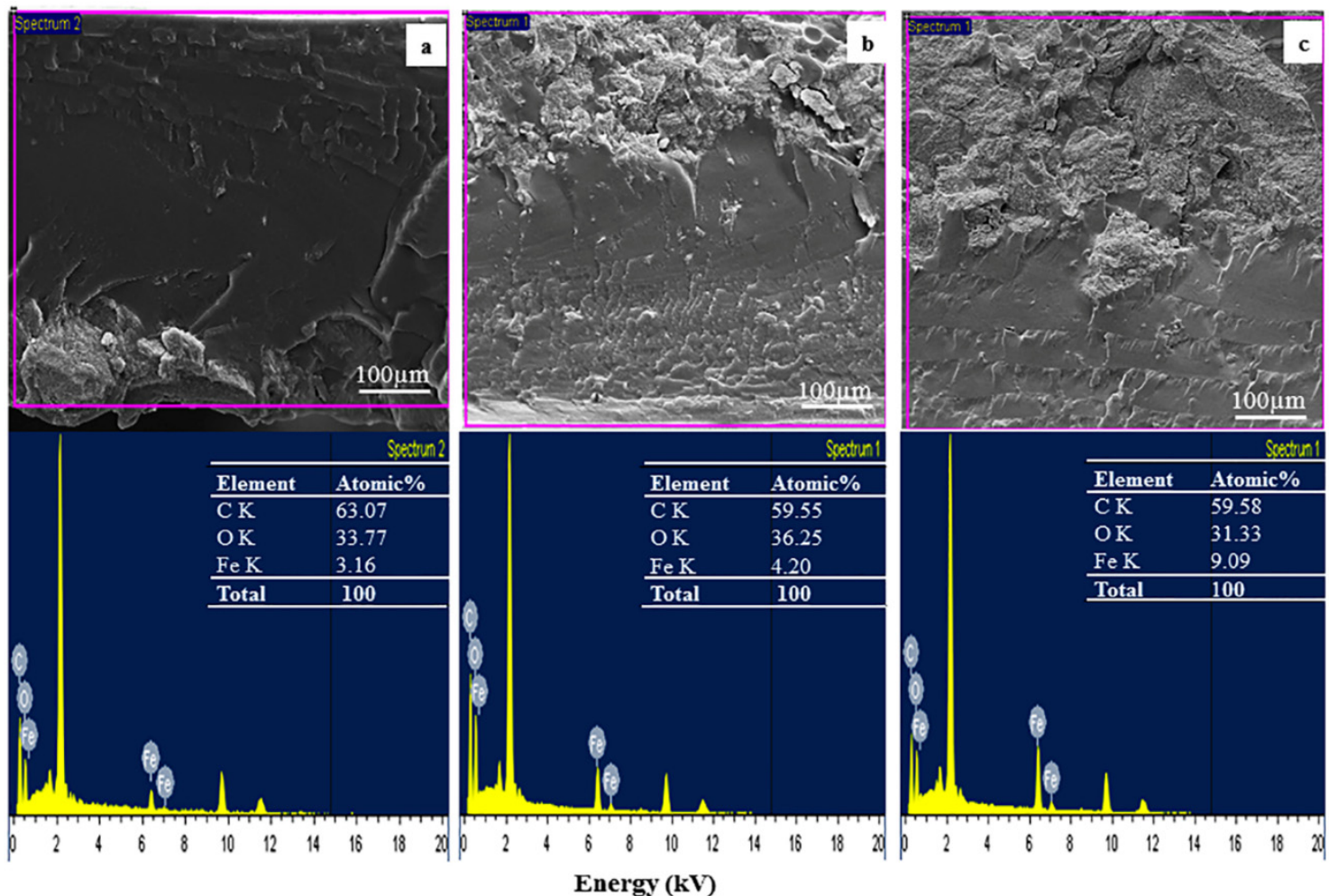

Figure 2. EDS analysis of (a) PVA/BM20, (b) PVA/BM40 and (c) PVA/BM60 composite films.
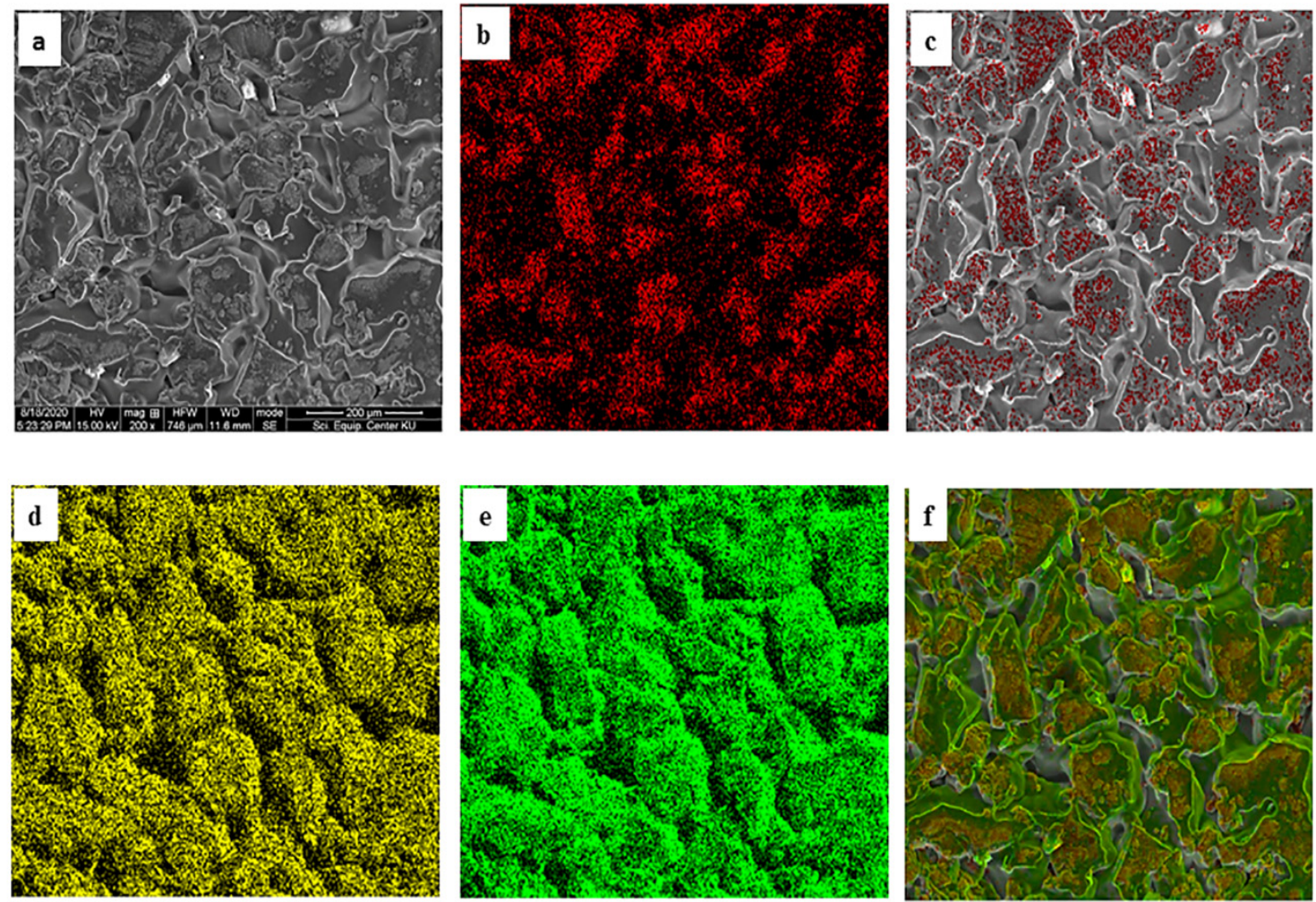

Figure 3. SEM micrograph (a) PVA/BM60 (200×), EDS elemental mapping of (b) Fe (red), (c) PVA/BM60_Fe mix, (d) O (yellow), (e) C (green) and (f) PVA/BM60_Fe_O_C mix composite film. 


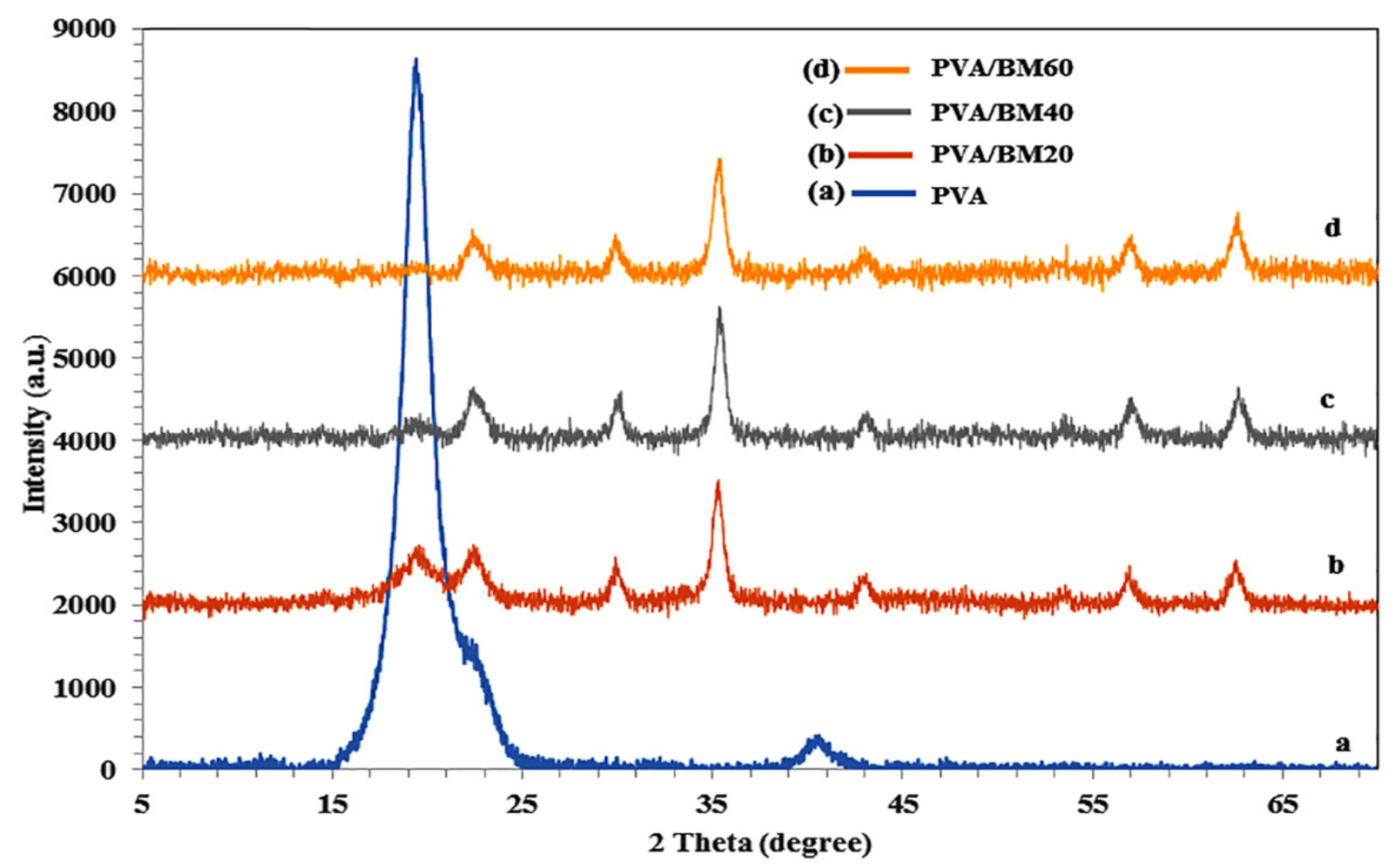

Figure 4. X-ray diffraction pattern of (a) PVA, (b) PVA/BM20, (c) PVA/BM40 and (d) PVA/BM60 composite films.

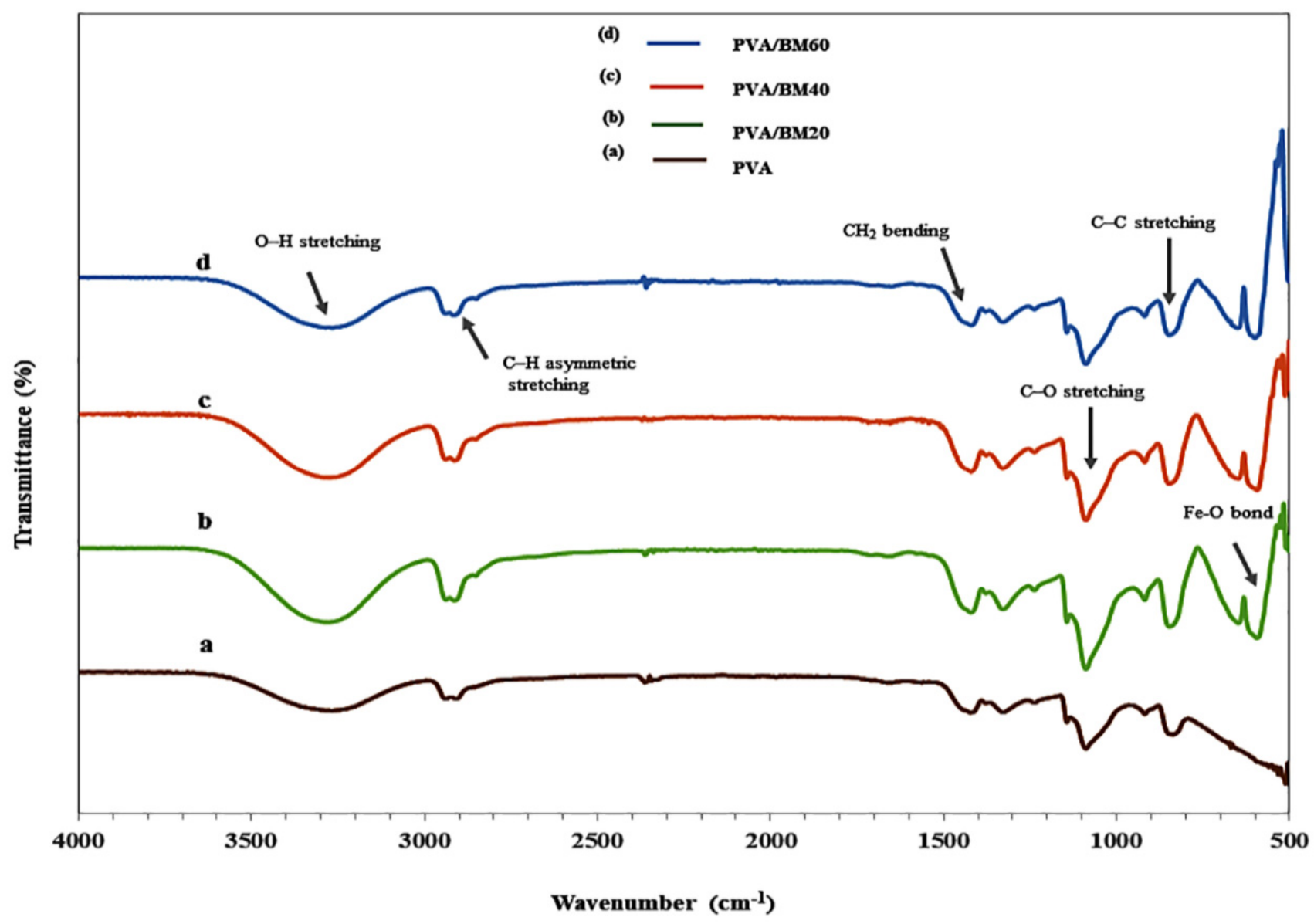

Figure 5. FTIR spectroscopy of (a) PVA, (b) PVA/BM20, (c) PVA/BM40 and (d) PVA/BM60. 


\subsection{XRD Analysis}

The diffraction pattern of the composite films with the characteristic fingerprints of the polymeric materials and magnetic nanoparticles are presented in Figure 4. The fingerprints reveal the chemical interaction of hydrogen bonds between nanoparticles and the PVA matrix [42]. The BCNC possessed a higher amount of hydroxyl groups and the PVA matrix, thus resulting in strong filler-matrix bonding in the film. The crystalline diffraction peaks of PVA are present at $2 \theta=19.4^{\circ}, 22.1^{\circ}$ and $40.4^{\circ}$ (Figure 4a). The peak at $2 \theta=19.4^{\circ}$ corresponded to an orthorhombic lattice of PVA, which specifies its crystalline nature. However, the incorporation of the nanoparticles resulted in a drastic decrease of the PVA peak intensity in the composite films. The presence of $\mathrm{Fe}_{3} \mathrm{O}_{4}$ in the film was confirmed by its fingerprint peaks at $2 \theta=30^{\circ}, 35.6^{\circ}, 43.2^{\circ}, 57.2^{\circ}$ and $62.9^{\circ}$, which corresponded with the crystal plane of (220), (311), (400), (511) and (440), respectively, based on the reference standard peak (JCPDS no. 019-0629) [43,44]. The crystalline peak of BCNC is observed at $2 \theta=22.6^{\circ}$, which corresponded to the (002) crystallographic plane, while the other minor peaks disappeared due to chemisorption of Fe ions by the hydroxyl group to form Fe-OH molecules. The intensity of PVA peaks continuously declined with increasing BM content in the PVA chains. The crystalline nature of the film was due to the strong intermolecular interaction between PVA chains through intermolecular hydrogen bonding. Nonetheless, the wide interplanar spacing could be attributed to the weak self-hydrogen bonding between PVA chains [45], which enabled successful interaction with BM in the composite films.

\subsection{FTIR Analysis}

To further interpret the intermolecular interactions of PVA with $\mathrm{BCNC}$ and $\mathrm{Fe}_{3} \mathrm{O}_{4}$, FTIR analysis was conducted to identify the various functional groups as presented in Figure 5. The pure PVA shows a wide absorption band traversing $3518-3122 \mathrm{~cm}^{-1}$, which is ascribed to the bonded hydroxyl $(\mathrm{O}-\mathrm{H}$ stretching) vibration in the crystalline phase due to the extensive H-bond [46]. The absorption peaks at 2914, 1415, 1080 and $839 \mathrm{~cm}^{-1}$ were apportioned to $\mathrm{C}-\mathrm{H}$ asymmetric stretching, $\mathrm{CH}_{2}$ bending, $\mathrm{C}-\mathrm{O}$ stretching and $\mathrm{C}-\mathrm{C}$ stretching, respectively. The incorporation of $\mathrm{BM}$ resulted in a slight broadening and increased intensity of the absorption peaks associated with $\mathrm{O}-\mathrm{H}$ stretching at 3556-3072, 3533-3122 and 3535-3130 $\mathrm{cm}^{-1}$ for PVA/BM20, PVA/BM40 and PVA/BM60, respectively. This may be attributed to the intermolecular bonding between the hydroxyl groups in PVA and BCNC [46]. However, the band at $2914 \mathrm{~cm}^{-1}$ for C-H asymmetric stretching remained the same with slight increase in peak intensity in the composite films. The slight changes recorded in the composite films could be attributed to the chemical interactions between the functional groups of the PVA matrix and $\mathrm{BCNC}$, which served as a binder between PVA and $\mathrm{Fe}_{3} \mathrm{O}_{4}$. The successful integration of $\mathrm{BCNC}$ and $\mathrm{Fe}_{3} \mathrm{O}_{4}$ nanoparticle in PVA was confirmed by the presence of two new absorption bands at 653.86 and $586.36-597.92 \mathrm{~cm}^{-1}$ in only the composite films, which were ascribed to Fe-O-C bonds between iron oxides and polymers. The fingerprint of $\mathrm{Fe}_{3} \mathrm{O}_{4}$ in the range of $586.36-597.92 \mathrm{~cm}^{-1}$ indicates the presence of $\mathrm{Fe}-\mathrm{O}$ bond of $\mathrm{Fe}_{3} \mathrm{O}_{4}$ [47]. The appearance of characteristic fingerprints of the various materials demonstrated successful synthesis of the ternary composite film.

\subsection{Vibrating Sample Magnetometer (VSM)}

The magnetic behavior of the films, which is a critical parameter of magnetic composites was evaluated by VSM. The VSM analysis was carried out and the results of hysteresis curves are presented in Figure 6. The saturation magnetization $(M S)$ value was derived from the VSM measurement at room temperature with the magnetic field of $\pm 10 \mathrm{kOe}$. The result shows a direct proportional increase in $M S$ with increasing BM in the film. The PVA/BM60 composite film recorded the highest $M S$ of $11.56 \mathrm{emu} / \mathrm{g}$, followed by PVA/BM40 (8.91 emu/g), while PVA/BM20 recorded $5.14 \mathrm{emu} / \mathrm{g}$. The MS values obtained in PVA/BM40 and 60 were higher than values reported in related studies [48-50]. The insert in Figure 6 shows the hysteresis loop upon the reversal of the applied magnetic 
field. The PVA/BM60 sample showed the highest amount of energy dissipation (hysteresis loop) compared with the other samples. This implies the ability of the film to retain a large fraction of the saturated magnetic field when the driving field was removed. The saturation magnetization is a function of temperature in the bulk magnetic material at low temperatures, therefore the high value of MS in PVA/BM60 is undeniably because of the high amount of BM present in the film. The films showed superparamagnetic properties with minimal remanent magnetization $(\mathrm{Mr} r)$ values of $0.212,0.378$ and $0.536 \mathrm{emu} / \mathrm{g}$ for PVA/BM20, PVA/BM40 and PVA/BM60, respectively. It is clear from the study that increasing the $\mathrm{BM}$ content will definitely increase the magnetic behavior of the film for the intended purpose. This is in agreement with previous studies where increasing $\mathrm{Fe}_{3} \mathrm{O}_{4}$ concentration (magnetic content) in the composite material, increases the sensitivity of the material to changes in external magnetic field with a subsequent increase in magnetic values $[12,51,52]$. However, an overdose of $\mathrm{Fe}_{3} \mathrm{O}_{4}$ content may lead to agglomeration, which may impede its dispersion in the matrix and uniform distribution of its magnetic moment. The superparamagnetic property and MS behavior of the film implies it could be responsive to alternating current magnetic fields for magnetic separation and adsorption of molecules and design of smart magnetic devices.

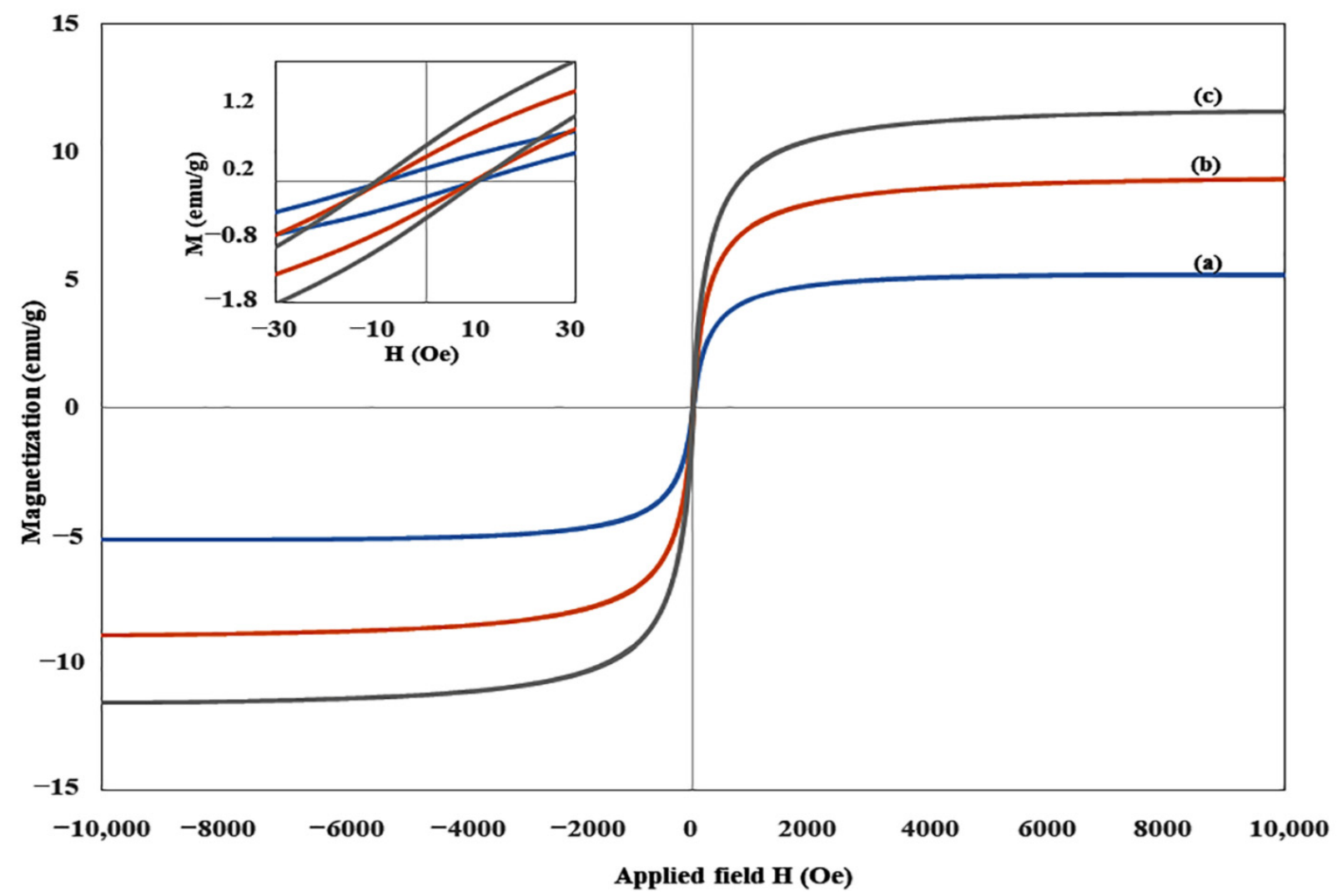

Figure 6. Field-dependent magnetization ( $\boldsymbol{M}$ versus $\boldsymbol{H}$ ) curves of (a) PVA/BM20, (b) PVA/BM40 and (c) PVA/BM60.

\subsection{Mechanical Strength}

The tensile test was performed to calculate the Young's modulus in order to determine the effect of the $\mathrm{BCNC}$ and $\mathrm{Fe}_{3} \mathrm{O}_{4}$ on the PVA film in terms of the maximum stress that a material can withstand and stiffness of the composites. The results presented in Table 1 show high significant difference $(p \leq 0.05)$ between pure PVA and PVA/BM composite films. The pure PVA recorded the highest tensile strength of $41.98 \pm 1.80 \mathrm{MPa}$ followed by PVA/BM20. Among the composites, there was a significant difference between PVA/BM20 and PVA/BM40 with tensile values of $24.36 \pm 1.70$ and $12.72 \pm 0.70 \mathrm{MPa}$, respectively. There was no significant difference between PVA/BM20 and PVA/BM60, which had a 
tensile value of $19.54 \pm 1.53 \mathrm{MPa}$. In terms of Young's modulus, there was no significant difference between the pure PVA, PVA/BM20 and PVA/BM40 films, which recorded $1.51 \pm 0.15,1.32 \pm 0.12$ and $1.58 \pm 0.02 \mathrm{GPa}$, respectively. However, increasing BM concentration to $60 \%$ resulted in a significant increase in the Young's modulus of PVA/BM60 composite film with a value of $2.35 \pm 0.16 \mathrm{GPa}$. The stress-strain curve (Figure 7) showed the percentage elongation at break of the samples. The introduction of BM led to a decrease in the elasticity of the films. The pure PVA had the highest percentage elongation of $169.9 \%$ followed by PVA/BM20 (50.8\%) and PVA/BM60 (32.0\%), while PVA/BM40 recorded the lowest elongation of $10.1 \%$. The decrease in value can be explained by the destruction of the samples at the initial stage of neck propagation as a result of thermomechanical instability of the samples when BM was added [53]. The high tensile strength and elongation at break of the pure PVA is laudable as it is an elastic material that can stretch when pulled before breaking. The decrease in the elasticity of the composite films could be a result of the solid particles inclusion and interactions between the PVA matrix and BM nanoparticles through the formation of mechanical and hydrogen bonds. The reinforced BM nanoparticles caused stiffening of the PVA matrix, which restricted the mobility of PVA molecular chains and subsequent reduction in flexibility of the nanocomposite films $[42,54]$. This was evident in the Young's modulus results, where the PVA/BM60 showed the highest stiffness. This is better than values reported in other literature $[50,55]$.

Table 1. The mechanical properties of pure PVA and PVA/BM composite films.

\begin{tabular}{ccc}
\hline Sample & Tensile Strength (MPa) & Young's Modulus (GPa) \\
\hline Pure PVA & $41.98 \pm 1.80^{\mathrm{c}}$ & $1.51 \pm 0.15^{\mathrm{a}}$ \\
PVA/BM20 & $24.36 \pm 1.70^{\mathrm{b}}$ & $1.32 \pm 0.12^{\mathrm{a}}$ \\
PVA/BM40 & $12.72 \pm 0.70^{\mathrm{a}}$ & $1.58 \pm 0.02^{\mathrm{a}}$ \\
PVA/BM60 & $19.54 \pm 1.53^{\mathrm{a}, \mathrm{b}}$ & $2.35 \pm 0.16^{\mathrm{b}}$ \\
\hline
\end{tabular}

Values with the same letter means the difference is not statistically significant, while different letters are statistically significant $(p \leq 0.05)$.

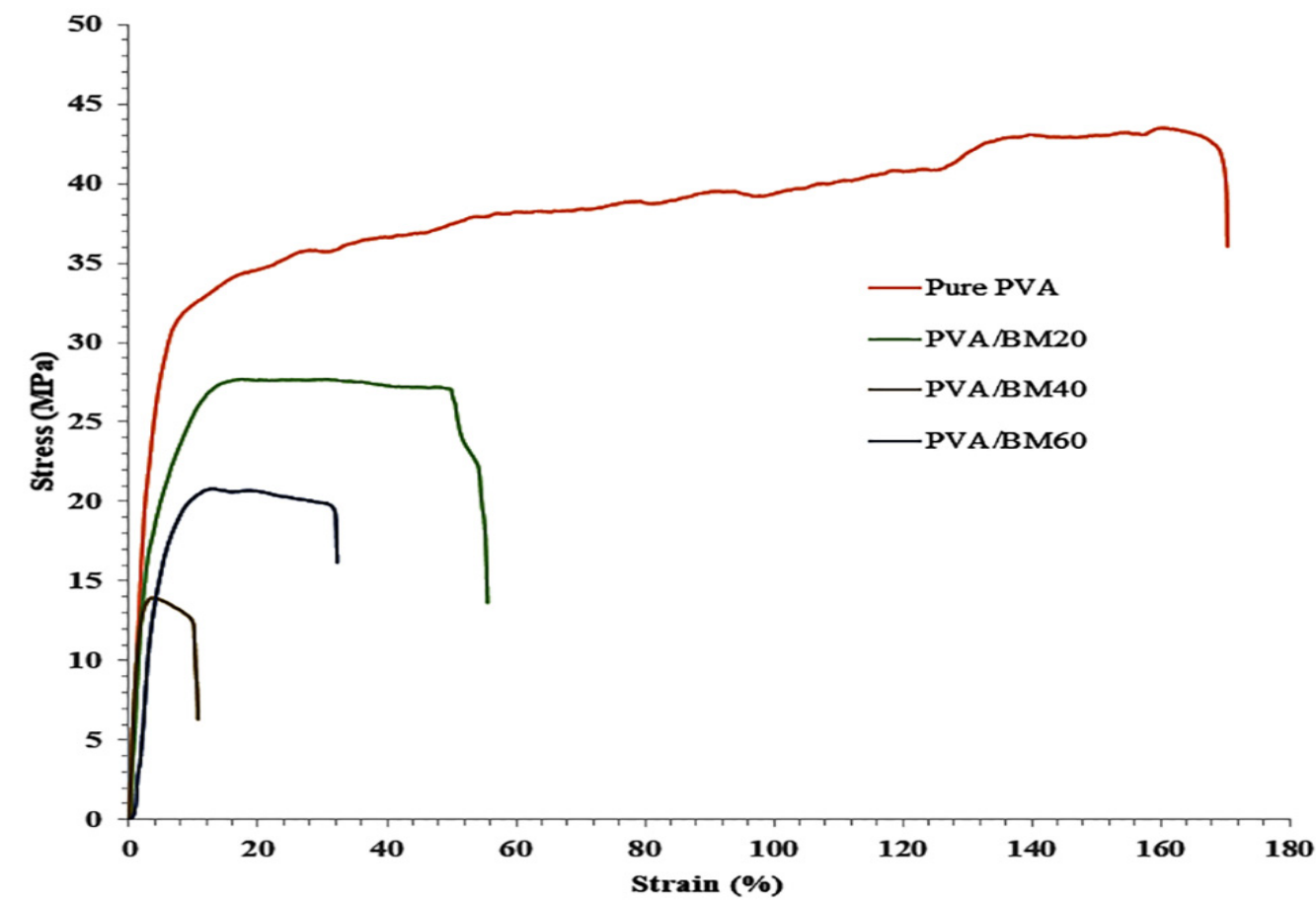

Figure 7. Stress-strain curve showing the break point of pure PVA, PVA/BM20, PVA/BM40 and PVA/BM60. 


\section{Conclusions}

The design of this study saw successful development of ternary magnetic nanoparticle and polymeric nanocomposite (PVA/BM) film. TEM analysis of BM showed irregular particles with an average size distribution of $22.94 \mathrm{~nm}$. The XRD and FTIR analysis showed the presence of functional groups of PVA, $\mathrm{BCNC}$ and $\mathrm{Fe}_{3} \mathrm{O}_{4}$ in the composite films. The distribution of the nanoparticles in the PVA film was confirmed by smart mapping of the elements present in the nanoparticles. Increasing the BM content resulted in an increase in the magnetic properties and Young's modulus of the film. The MS exhibited by PVA/BM60 with superparamagnetic property would guarantee an efficient heating under an oscillating magnetic field, which is promising for the design of smart electronic devices. It can also be manipulated by external magnetic fields and reused multiple times in adsorption of molecules. This study serves as the foundation for fabricating an environmentally friendly, sustainable and naturally renewable green adsorbent and smart electronic devices.

Supplementary Materials: The following are available online at https: / www.mdpi.com/article / $10.3390 /$ polym13111778/s1, Figure S1. AFM micrograph of (a) bacterial cellulose nanocrystals $(1 \times 1 \mu \mathrm{m})$ and (b) magnetite nanoparticles $(2 \times 2 \mu \mathrm{m})$; Figure S2. SEM micrograph of (a) PVA, (b) PVA/BM20, (c) PVA/BM40 and (d) PVA/BM60 composite films.

Author Contributions: Conceptualization, S.T. and P.S. (Prakit Sukyai); methodology, S.T.; software, S.T.; validation, S.T.; formal analysis, N.U. and S.T.; investigation, N.U. and S.T.; resources, P.S. (Prakit Sukyai), S.K., B.P. and P.S. (Preeyanuch Srichola); data curation, S.T.; writing-original draft preparation, N.U. and S.T.; writing-review and editing, S.T., P.S. (Prakit Sukyai), S.K., B.P. and P.S. (Preeyanuch Srichola); visualization, S.T.; supervision, P.S. (Prakit Sukyai); project administration, P.S. (Prakit Sukyai); funding acquisition, P.S. (Prakit Sukyai). All authors have read and agreed to the published version of the manuscript.

Funding: This research was funded by Kasetsart University Research and Development Institute, grant number FF(KU) 25.64, under the Development of Advance Research Competence System for Competitiveness in Agriculture and Food.

Institutional Review Board Statement: Not applicable.

Informed Consent Statement: Not applicable.

Data Availability Statement: The data presented in this study are available on request from the corresponding author.

Acknowledgments: This research was supported by Kasetsart University Research and Development Institute, grant number FF(KU) 25.64, under the Development of Advance Research Competence System for Competitiveness in Agriculture and Food The authors are grateful to the Department of Biotechnology, Faculty of Agro-Industry, Kasetsart University for all laboratory equipment and instruments.

Conflicts of Interest: The authors declare there is no conflict of interest.

\section{References}

1. Kalubowilage, M.; Janik, K.; Bossmann, S.H. Magnetic Nanomaterials for Magnetically-Aided Drug Delivery and Hyperthermia. Appl. Sci. 2019, 9, 2927. [CrossRef]

2. Carlos, L.; Einschlag, F.S.G.; González, M.C.; Mártire, D.O. Applications of magnetite nanoparticles for heavy metal removal from wastewater. Waste Water Treat. Technol. Recent Anal. Dev. 2013, 3, 63-77.

3. Berensmeier, S. Magnetic particles for the separation and purification of nucleic acids. Appl. Microbiol. Biotechnol. 2006, 73, 495-504. [CrossRef] [PubMed]

4. Li, J.; Jiang, B.; Liu, Y.; Qiu, C.; Hu, J.; Qian, G.; Guo, W.; Ngo, H.H. Preparation and adsorption properties of magnetic chitosan composite adsorbent for $\mathrm{Cu} 2+$ removal. J. Clean. Prod. 2017, 158, 51-58. [CrossRef]

5. Wang, J.; Zheng, S.; Shao, Y.; Liu, J.; Xu, Z.; Zhu, D. Amino-functionalized $\mathrm{Fe}_{3} \mathrm{O}_{4} @ \mathrm{SiO}_{2}$ core-shell magnetic nanomaterial as a novel adsorbent for aqueous heavy metals removal. J. Colloid Interface Sci. 2010, 349, 293-299. [CrossRef]

6. Huang, Y.; Fulton, A.N.; Keller, A.A. Simultaneous removal of PAHs and metal contaminants from water using magnetic nanoparticle adsorbents. Sci. Total. Environ. 2016, 571, 1029-1036. [CrossRef] 
7. Yantasee, W.; Warner, C.L.; Sangvanich, T.; Addleman, R.S.; Carter, T.G.; Wiacek, R.J.; Warner, M.G. Removal of Heavy Metals from Aqueous Systems with Thiol Functionalized Superparamagnetic Nanoparticles. Environ. Sci. Technol. 2007, 41, 5114-5119. [CrossRef]

8. Zhang, Y.; Xu, Q.; Zhang, S.; Liu, J.; Zhou, J.; Xu, H.; Xiao, H.; Li, J. Preparation of thiol-modified $\mathrm{Fe}_{3} \mathrm{O}_{4} @ \mathrm{SiO}_{2}$ nanoparticles and their application for gold recovery from dilute solution. Sep. Purif. Technol. 2013, 116, 391-397. [CrossRef]

9. Fatima, H.; Kim, K.-S. Magnetic nanoparticles for bioseparation. Korean J. Chem. Eng. 2017, 34, 589-599. [CrossRef]

10. Kim, S.-E.; Van Tieu, M.; Hwang, S.Y.; Lee, M.-H. Magnetic Particles: Their Applications from Sample Preparations to Biosensing Platforms. Micromachines 2020, 11, 302. [CrossRef]

11. Akhbarizadeh, R.; Shayestefar, M.R.; Darezereshki, E. Competitive Removal of Metals from Wastewater by Maghemite Nanoparticles: A Comparison Between Simulated Wastewater and AMD. Mine Water Environ. 2014, 33, 89-96. [CrossRef]

12. Kloster, G.A.; Muraca, D.; Londoño, O.M.; Pirota, K.R.; Mosiewicki, M.A.; Marcovich, N.E. Alginate based nanocomposites with magnetic properties. Compos. Part A Appl. Sci. Manuf. 2020, 135, 105936. [CrossRef]

13. Yudha, S.P.; Tekasakul, S.; Phoungthong, K.; Chuenchom, L. Green synthesis of low-cost and eco-friendly adsorbent for dye and pharmaceutical adsorption: Kinetic, isotherm, thermodynamic and regeneration studies. Mater. Res. Express 2019, 6, 125526. [CrossRef]

14. Lin, T.-C.; Lin, F.-H.; Lin, J.-C. In vitro feasibility study of the use of a magnetic electrospun chitosan nanofiber composite for hyperthermia treatment of tumor cells. Acta Biomater. 2012, 8, 2704-2711. [CrossRef]

15. Wang, S.; Sun, Z.; Yan, E.; Yuan, J.; Gao, Y.; Bai, Y.; Chen, Y.; Wang, C.; Zheng, Y.; Jing, T. Magnetic composite nanofibers fabricated by electrospinning of Fe3O4/gelatin aqueous solutions. Mater. Sci. Eng. B 2014, 190, 126-132. [CrossRef]

16. Hong, X.; Guo, W.; Yuan, H.; Li, J.; Liu, Y.; Ma, L.; Bai, Y.; Li, T. Periodate oxidation of nanoscaled magnetic dextran composites. J. Magn. Magn. Mater. 2004, 269, 95-100. [CrossRef]

17. Brunsen, A.; Utech, S.; Maskos, M.; Knoll, W.; Jonas, U. Magnetic Composite Thin Films of FexOy Nanoparticles and Photocrosslinked Dextran Hydrogels. J. Magn. Magn. Mater. 2012, 324, 1488-1497. [CrossRef]

18. Saranya, D.; Rajan, R.; Suganthan, V.; Murugeswari, A.; Raj, N.A.N. Synthesis and Characterization of Pullulan Acetate Coated Magnetic Nanoparticle for Hyperthermic Therapy. Procedia Mater. Sci. 2015, 10, 2-9. [CrossRef]

19. Castrejón-Parga, K.Y.; Camacho-Montes, H.; Rodríguez-González, C.A.; Velasco-Santos, C.; Martinez-Hernandez, A.L.; BuenoJaquez, D.; Rivera-Armenta, J.L.; Ambrosio, R.; Conzalez, C.C.; Mendoza-Duarte, M.E.; et al. Chitosan-starch film reinforced with magnetite-decorated carbon nanotubes. J. Alloys Compd. 2014, 615, S505-S510. [CrossRef]

20. Chen, W.; Yi, P.; Zhang, Y.; Zhang, L.; Deng, Z.; Zhang, Z. Composites of Aminodextran-Coated Fe3O4 Nanoparticles and Graphene Oxide for Cellular Magnetic Resonance Imaging. ACS Appl. Mater. Interfaces 2011, 3, 4085-4091. [CrossRef]

21. Lam, N.T.; Saewong, W.; Sukyai, P. Effect of varying hydrolysis time on extraction of spherical bacterial cellulose nanocrystals as a reinforcing agent for poly(vinyl alcohol) composites. J. Polym. Res. 2017, 24, 71. [CrossRef]

22. Singhsa, P.; Narain, R.; Manuspiya, H. Bacterial Cellulose Nanocrystals (BCNC) Preparation and Characterization from Three Bacterial Cellulose Sources and Development of Functionalized BCNCs as Nucleic Acid Delivery Systems. ACS Appl. Nano Mater. 2018, 1, 209-221. [CrossRef]

23. DeMerlis, C.; Schoneker, D. Review of the oral toxicity of polyvinyl alcohol (PVA). Food Chem. Toxicol. 2003, 41, 319-326. [CrossRef]

24. Muppalaneni, S.; Omidian, H. Polyvinyl Alcohol in Medicine and Pharmacy: A Perspective. J. Dev. Drugs 2013, 2, 1-5. [CrossRef]

25. Reddy, P.L.; Deshmukh, K.; Kováŕík, T.; Reiger, D.; Nambiraj, N.A.; Lakshmipathy, R. Enhanced dielectric properties of green synthesized Nickel Sulphide (NiS) nanoparticles integrated polyvinylalcohol nanocomposites. Mater. Res. Express 2020, 7, 064007. [CrossRef]

26. Reddy, P.L.; Deshmukh, K.; Chidambaram, K.; Ali, M.M.N.; Sadasivuni, K.K.; Kumar, Y.R.; Lakshmipathy, R.; Pasha, S.K.K. Dielectric properties of polyvinyl alcohol (PVA) nanocomposites filled with green synthesized zinc sulphide (ZnS) nanoparticles. J. Mater. Sci. Mater. Electron. 2019, 30, 4676-4687. [CrossRef]

27. Reddy, P.L.; Deshmukh, K.; Kováŕík, T.; Nambiraj, N.A.; Shaik, K.P. Green chemistry mediated synthesis of cadmium sulphide/polyvinyl alcohol nanocomposites: Assessment of microstructural, thermal, and dielectric properties. Polym. Compos. 2020, 41, 2054-2067. [CrossRef]

28. Pandey, M.; Joshi, G.M.; Deshmukh, K.; Khutia, M.; Ghosh, N.N. Optimized AC conductivity correlated to structure, morphology and thermal properties of PVDF/PVA/Nafion composites. Ionics 2014, 20, 1427-1433. [CrossRef]

29. Xue, B.; Tong, X.D.; Sun, Y. Characterization of Pva-Based Magnetic Affinity Support for Protein Adsorption. Sep. Sci. Technol. 2001, 36, 2449-2461. [CrossRef]

30. Tong, X.; Xue, B.; Sun, Y. A Novel Magnetic Affinity Support for Protein Adsorption and Purification. Biotechnol. Prog. 2001, 17, 134-139. [CrossRef] [PubMed]

31. Mohammadi, N.S.; Khiabani, M.S.; Ghanbarzadeh, B.; Mokarram, R.R. Enhancement of biochemical aspects of lipase adsorbed on halloysite nanotubes and entrapped in a polyvinyl alcohol/alginate hydrogel: Strategies to reuse the most stable lipase. World J. Microbiol. Biotechnol. 2020, 36, 1-15. [CrossRef]

32. Soleymani, M.; Akbari, A.; Mahdavinia, G.R. Magnetic PVA/laponite RD hydrogel nanocomposites for adsorption of model protein BSA. Polym. Bull. 2019, 76, 2321-2340. [CrossRef]

33. Deng, S.; Xu, H.; Jiang, X.; Yin, J. Poly(vinyl alcohol) (PVA)-Enhanced Hybrid Hydrogels of Hyperbranched Poly(ether amine) (hPEA) for Selective Adsorption and Separation of Dyes. Macromolecules 2013, 46, 2399-2406. [CrossRef] 
34. Ahmad, J.; Deshmukh, K.; Hägg, M.B. Influence of TiO2 on the Chemical, Mechanical, and Gas Separation Properties of Polyvinyl Alcohol-Titanium Dioxide (PVA-TiO2) Nanocomposite Membranes. Int. J. Polym. Anal. Charact. 2013, 18, 287-296. [CrossRef]

35. Rahayu, L.B.H.; Wulandari, I.O.; Santjojo, D.H.; Sabarudin, A. Synthesis and Characterization of Fe3O4 Nanoparticles using Polyvinyl Alcohol (PVA) as Capping Agent and Glutaraldehyde (GA) as Crosslinker. IOP Conf. Ser. Mater. Sci. Eng. 2018, 299, 12062. [CrossRef]

36. Torgbo, S.; Sukyai, P. Fabrication of microporous bacterial cellulose embedded with magnetite and hydroxyapatite nanocomposite scaffold for bone tissue. Eng. Mater. Chem. Phys. 2019, 237, 121868. [CrossRef]

37. Yingkamhaeng, N.; Intapan, I.; Sukyai, P. Fabrication and Characterisation of Functionalised Superparamagnetic Bacterial Nanocellulose Using Ultrasonic-Assisted In Situ Synthesis. Fibers Polym. 2018, 19, 489-497. [CrossRef]

38. Sucharitpong, T.; Lam, N.T.; Sukyai, P. Production of Nylon-6/Cellulose Nanocrystal Composite Films Using Solvent Dissolution. Sugar Tech. 2019, 22, 328-339. [CrossRef]

39. Abenojar, E.C.; Wickramasinghe, S.; Bas-Concepcion, J.; Samia, A.C.S. Structural effects on the magnetic hyperthermia properties of iron oxide nanoparticles. Prog. Nat. Sci. 2016, 26, 440-448. [CrossRef]

40. Ojemaye, M.O.; Okoh, O.O.; Okoh, A.I. Surface modified magnetic nanoparticles as efficient adsorbents for heavy metal removal from wastewater: Progress and prospects. Mater. Express 2017, 7, 439-456. [CrossRef]

41. Dallas, P.; Georgakilas, V.; Niarchos, D.; Komninou, P.; Kehagias, T.; Petridis, D. Synthesis, characterization and thermal properties of polymer/magnetite nanocomposites. Nanotechnology 2006, 17, 2046-2053. [CrossRef]

42. Mousa, M.; Dong, Y. The Role of Nanoparticle Shapes and Structures in Material Characterisation of Polyvinyl Alcohol (PVA) Bionanocomposite Films. Polymers 2020, 12, 264. [CrossRef]

43. Abbas, M.; Rao, B.P.; Naga, S.; Takahashi, M.; Kim, C. Synthesis of high magnetization hydrophilic magnetite (Fe3O4) nanoparticles in single reaction-Surfactantless polyol process. Ceram. Int. 2013, 39, 7605-7611. [CrossRef]

44. Ouyang, Z.-W.; Chen, E.-C.; Wu, T.-M. Thermal Stability and Magnetic Properties of Polyvinylidene Fluoride/Magnetite Nanocomposites. Materials 2015, 8, 4553-4564. [CrossRef] [PubMed]

45. Liu, P.; Chen, W.; Liu, C.; Tian, M.; Liu, P. A novel poly (vinyl alcohol)/poly (ethylene glycol) scaffold for tissue engineering with a unique bimodal open-celled structure fabricated using supercritical fluid foaming. Sci. Rep. 2019, 9, 1-12. [CrossRef] [PubMed]

46. Cazón, P.; Velázquez, G.; Vázquez, M. Characterization of bacterial cellulose films combined with chitosan and polyvinyl alcohol: Evaluation of mechanical and barrier properties. Carbohydr. Polym. 2019, 216, 72-85. [CrossRef] [PubMed]

47. Chaichi, M.; Sharif, F.; Mazinani, S. Preparation and evaluation of magnetic field-induced orientation on magnetic nanoparticles on PVA nanocomposite films. J. Mater. Sci. 2017, 53, 5051-5062. [CrossRef]

48. Dahlan, N.A.; Veeramachineni, A.K.; Langford, S.J.; Pushpamalar, J. Developing of a magnetite film of carboxymethyl cellulose grafted carboxymethyl polyvinyl alcohol (CMC-g-CMPVA) for copper removal. Carbohydr. Polym. 2017, 173, 619-630. [CrossRef]

49. Ramezan zadeh, M.H.; Seifi, M. Synthesis and physical investigation of PVA-based cast films reinforced with non-covalently functionalized magnetite-deposited carbon nanotubes. Mater. Res. Express 2019, 6, 066113. [CrossRef]

50. Wang, Y.; Zhu, Y.; Xue, Y.; Wang, J.; Li, X.; Wu, X.; Qin, Y.; Chen, W. Sequential in-situ route to synthesize novel composite hydrogels with excellent mechanical, conductive, and magnetic responsive properties. Mater. Des. 2020, 193, 108759. [CrossRef]

51. Kholifah, M.N.; Taufiq, A.; Mufti, N.; Wulandari, R.; Diantoro, M. Deformation of Ferrogel Based on Carboxyl Methyl Cellulose (CMC)/Polyvinyl Alcohol (PVA) Hydrogel. IOP Conf. Ser. Mater. Sci. Eng. 2018, 367, 012016.

52. Czaun, M.; Hevesi, L.; Takafuji, M.; Ihara, H. A novel approach to magneto-responsive polymeric gels assisted by iron nanoparticles as nano cross-linkers. Chem. Commun. 2008, 18, 2124-2126. [CrossRef]

53. Bazhenov, S.L.; Manevich, L.I. Criterion for neck-propagation stability in polymers. Polym. Sci. Ser. A 2010, 52, 168-174. [CrossRef]

54. Oréfice, R.L.; Hench, L.L.; Brennan, A.B. Effect of particle morphology on the mechanical and thermo-mechanical behavior of polymer composites. J. Braz. Soc. Mech. Sci. 2001, 23, 1-8. [CrossRef]

55. Bannerman, A.D.; Li, X.; Wan, W. A 'degradable' poly (vinyl alcohol) iron oxide nanoparticle hydrogel. Acta Biomater. 2017, 58, 376-385. [CrossRef] 